\title{
TAS-303 effects on urethral sphincter function in women with stress urinary incontinence: phase I study
}

\author{
Makoto Yono ${ }^{1,2}$ (1) $\cdot$ Shin Irie ${ }^{3,4} \cdot$ Momokazu Gotoh $^{5,6}$ \\ Received: 31 March 2020 / Accepted: 23 July 2020 / Published online: 10 October 2020 \\ (C) The Author(s) 2020
}

\begin{abstract}
Introduction and hypothesis TAS-303, which selectively inhibits noradrenaline reuptake, was developed for treating stress urinary incontinence (SUI). The proximal urethra mainly comprises smooth muscle fibers in which $\alpha 1$ adrenergic receptors are abundant. This study was conducted to evaluate the effect of TAS-303 on urethral function and its safety profile in female patients with SUI.

Methods In total, 16 women (age, 20-64 years) with SUI and $>5.0 \mathrm{~g}$ of leakage in the 1-h pad test at screening were randomized and administered the assigned treatment in a double-blind manner. The primary end point was change in the maximal urethral closure pressure (MUCP) at $6 \mathrm{~h}$ post-dose. The secondary end point was change in the urethral closure pressure of the entire urethra and each urethral region (proximal, middle, and distal) at $6 \mathrm{~h}$ post-dose. The results were analyzed using a t-test.

Results The mean change \pm standard deviation in MUCP at $6 \mathrm{~h}$ post-dose was $3.473 \pm 12.154 \mathrm{cmH}_{2} \mathrm{O}$ for TAS-303 and $2.615 \pm$ $9.794 \mathrm{cmH}_{2} \mathrm{O}$ for placebo (between-group difference: $0.858 \mathrm{cmH}_{2} \mathrm{O}, P=0.8047$ ). The mean changes \pm standard deviation in urethral closure pressure of the proximal urethra at $6 \mathrm{~h}$ after the administration of TAS-303 $18 \mathrm{mg}$ and placebo were $3.863 \pm$ 10.941 and $1.634 \pm 12.093$, respectively (between-group difference: $2.229 \mathrm{cmH}_{2} \mathrm{O}, P=0.5976$ ).

Conclusions No significant difference in MUCP and urethral closure pressure was found between TAS-303 and placebo. However, the change in the proximal urethral closure pressure with TAS-303 was larger than that with placebo. This suggests that TAS-303 has pharmacological effects on urethral sphincteric function.
\end{abstract}

Keywords Japan $\cdot$ Maximum urethral closure pressure $\cdot$ Randomized controlled study $\cdot$ Stress urinary incontinence $\cdot$ TAS-303 . Urethral pressure profile parameters

Electronic supplementary material The online version of this article (https://doi.org/10.1007/s00192-020-04470-7) contains supplementary material, which is available to authorized users.

Makoto Yono

m-yonou@nishikuma.com

1 Department of Urology, Nishi Kumamoto Hospital, Souseikai, Kumamoto, Japan

21012 Koga, Tomiai-machi, Minami-ku, Kumamoto 861-4157, Japan

3 Department of Clinical Pharmacology, Nishi Kumamoto Hospital, Souseikai, Kumamoto, Japan

4 Present address: Souseikai, Fukuoka, Japan

5 Department of Urology, Nagoya University Graduate School of Medicine, Aichi, Japan

6 Present address: Chukyo Hospital, Aichi, Japan

\section{Introduction}

Stress urinary incontinence (SUI), defined as a "complaint of involuntary loss of urine on effort or physical exertion or on sneezing or coughing" by the International Continence Society [1], is a common health problem among women and has a significant negative impact on quality of life [2-4].

According to the clinical guidelines on urinary incontinence in the European Union [5, 6] and female lower urinary tract symptoms in Japan [7], for all female patients with SUI, initial management includes pharmacotherapy as well as lifestyle interventions and pelvic floor muscle training. Indeed, duloxetine (approved in the European Union) and clenbuterol (approved in Japan) are used as a treatment for women with SUI in the European Union and Japan, respectively. Female patients who have failed initial management and are bothered by their symptoms and an impaired QoL are likely to request further treatment, e.g., surgery. It is thus conceivable that if initial management has been exhausted, surgery for SUI may 
be indicated. However, owing to the difficulty in performing long-term pelvic floor muscle exercises, as well as concerns regarding the invasiveness and safety of surgery, the clinical need for a new SUI treatment remains unmet $[8,9]$.

TAS-303, developed by Taiho Pharmaceutical for treating SUI, selectively inhibits noradrenaline reuptake without centrally mediated antidepressant activity. In animal studies, TAS-303 increased the urethral basal pressure in normal rats and increased the leak point pressure in a rat vaginal distension model, suggesting its potential efficacy for treating SUI [10].

Considering the mechanism of action (increasing the urethral pressure) of TAS-303, the maximum urethral closure pressure (MUCP) was presumed to be an appropriate urodynamic parameter and was determined to be the primary study end point according to Section 6.2.3 ("Stress incontinence") of the European Medicine Agency clinical investigation guideline [11]. MUCP can be used in proofof-mechanism studies of new drugs developed to treat SUI [12]. The proximal urethra mainly consists of smooth muscle fibers in which $\alpha 1$ receptors are abundant [13, 14]. Therefore, we considered the proximal urethra appropriate for evaluating the mechanism of action of TAS303.

The primary aim of this phase I study was to evaluate the effects of a single oral dose (18 mg) of TAS-303 on MUCP in women with SUI. The secondary objectives were to assess the effects of TAS-303 on the MUCP of different urethral regions and also to investigate the pharmacokinetics (PK) and the safety of TAS-303.

\section{Materials and methods}

\section{Study design and treatment}

This was a single-center, randomized, double-blind, placebo-controlled, two-period cross-over, single-dose, phase I study conducted in the period from October to December 2015 at Nishi Kumamoto Hospital in Japan. The study design is shown in Supplementary Fig. 1. Sixteen patients with predominant SUI were randomized to either group A (TAS$30318 \mathrm{mg}$ followed by placebo) or group B (placebo followed by TAS-303 $18 \mathrm{mg}$ ) at a 1:1 ratio (eight patients per group). The study comprised two periods in which TAS$30318 \mathrm{mg}$ or placebo was administered as a single oral dose in a double-blind manner. In period 1, patients deemed eligible for the study at screening were hospitalized the day before study drug administration (day -1), administered a single oral dose of the study drug on day 1 , and discharged from the study site with no identified safety concerns on day 4. Measurement of urethral closure pressure was conducted before administration and $6 \mathrm{~h}$ post-dose. Subsequently, period 2 was started and followed the same procedures as period 1 (admission to the study site on day 14 followed by a single administration of the study drug on day 15 and discharge on day 18). Between 14 and 21 days post-dose in period 2, the patients returned to the study site for follow-up evaluation. The patients were not permitted to lie down for $4 \mathrm{~h}$ post-dose unless this was needed for clinical assessments.

To prevent infections, levofloxacin was administered as a single oral dose of $500 \mathrm{mg}$ after each measurement of urethral pressure. The prohibited concomitant medications and therapies and the details of randomization and blinding are described in Supplementary Methods.

This trial was conducted in accordance with the Good Clinical Practice Guidelines and the Declaration of Helsinki. The protocol and informed consent form were approved by the Institutional Review Board at Hakata Clinic (Souseikai Global Clinical Research Center) in Japan. Written informed consent was obtained from all study participants. This study was registered at ClinicalTrials.gov (NCT02562807).

\section{Patients}

Women aged 20 to $<65$ years with predominant SUI, body mass index (BMI) of 18.0 to $<30.0 \mathrm{~kg} / \mathrm{m}^{2}$, and leakage of $>$ $5.0 \mathrm{~g}$ in the $1-\mathrm{h}$ pad test at screening were included in this study. Patients with predominant urge urinary incontinence, a history of surgical therapy for SUI, and/or presence of pelvic organ prolapse were excluded.

\section{Efficacy endpoints}

The primary end point was the change in MUCP at $6 \mathrm{~h}$ postdose. The secondary end points were urethral pressure profile (UPP) parameters, including changes in MUCP and mean urethral closure pressure at rest for the entire urethra and for the proximal, middle, and distal thirds of the functional urethral length at $6 \mathrm{~h}$ post-dose. The measurement time of MUCP was $6 \mathrm{~h}$ post-dose because $C_{\max }$ was $6 \mathrm{~h}$ when $18 \mathrm{mg}$ was administered in a single-dose phase I study in healthy adult males (unpublished data).

The functional urethral length was automatically divided into three sections using Duet software (Mediwatch, Rugby, UK). The proximal, middle, and distal thirds of the urethra were defined as $30 \%, 40 \%$, and $30 \%$ of the total length of the functional urethra, respectively.

The mean and maximum values for each UPP parameter were calculated for the entire urethra and for individual regions. The UPP parameter was measured three times. The mean and maximum values calculated from three successive profiles were averaged within each patient. 


\section{Safety end points}

Adverse events (AEs) and adverse drug reactions, physical findings, blood pressure, pulse rate, body temperature, 12lead electrocardiography findings, and laboratory test results were evaluated to determine the safety of TAS-303. AE data were collected and coded using MedDRA ${ }^{\circledR}$ (version 18.1) terms. The severity of AEs was evaluated and classified using Common Terminology Criteria for Adverse Events version 4.0, Japan Clinical Oncology Group edition version 4.03.

\section{PK analysis}

The plasma concentrations of TAS-303 were measured at Shin Nippon Biomedical Laboratories, Ltd., using validated liquid chromatography/tandem mass spectrometry. The following PK parameters of TAS-303 were evaluated using Phoenix ${ }^{\circledR}$ WinNonlin ${ }^{\circledR}$ (version 6.4; Certara, LP, Princeton, NJ, USA): maximum plasma concentration $\left(\mathrm{C}_{\max }\right)$, time to maximum plasma concentration $\left(t_{\max }\right)$, area under the plasma concentration-time curve from time zero to the final time of detection $\left(\mathrm{AUC}_{0 \text {-last }}\right)$, area under the plasma concentration versus time curve from time zero to infinity $\left(\mathrm{AUC}_{0 \text {-inf }}\right)$, and elimination half-time $\left(\mathrm{t}_{1 / 2}\right)$.

\section{Urethral pressure measurement}

Urethral pressure was measured in accordance with the Report from the Standardization Subcommittee of the International Continence Society [15]. The UPP parameters at rest were measured before and $6 \mathrm{~h}$ after administering TAS-303 $18 \mathrm{mg}$ and placebo. Three successive profiles were measured with the patient resting and in the absence of bladder stimulation. Additional details are provided in Supplementary Methods.

\section{Statistical analysis}

The target sample size of 16 patients was not statistically determined considering the invasiveness of this urethral pressure measurement method. Data are shown as mean \pm standard deviation. Summary statistics for the changes in MUCP in the entire urethra and in each urethral region and two-sided 95\% confidence intervals (CIs) were calculated with respect to each group. Differences in the changes in MUCP between groups were analyzed using a t-test. The safety analysis set comprised all randomized patients who received one dose of the study drug. The primary and secondary efficacy end points were assessed in the full analysis set, comprising all randomized patients who received at least one dose of the study drug, met all the inclusion criteria and none of the exclusion criteria, and had primary end point data at periods 1 and 2. Data were analyzed using SAS software, version 9.2 (SAS Institute, Cary, NC, USA).

\section{Results}

The flow of patient disposition is shown in Fig. 1. Thirty-two patients provided informed consent; 22 patients were eligible at screening; 16 women were randomized. All randomized patients received the study drug: eight were assigned to group A (TAS-303 $18 \mathrm{mg}$ followed by placebo) and eight were assigned to group B (placebo followed by TAS-303 $18 \mathrm{mg}$ ). All patients completed the study.

The median age was 53.0 (range 23-62) years, and the median BMI was 20.69 (range: $18.5-29.7$ ) $\mathrm{kg} / \mathrm{m}^{2}$. Ten patients had SUI, and six had mixed urinary incontinence (Supplementary Table 1).

\section{Efficacy}

\section{Urethral pressure at rest}

The mean change \pm standard deviation $(95 \% \mathrm{CI})$ in MUCP at $6 \mathrm{~h}$ post-dose (primary end point) was $3.473 \pm 12.154(-3.003$ to 9.949$) \mathrm{cmH}_{2} \mathrm{O}$ for TAS-303 $18 \mathrm{mg}$ and $2.615 \pm 9.794$ ( -2.604 to 7.834$) \mathrm{cmH}_{2} \mathrm{O}$ for placebo, with a between-group difference of $0.858 \mathrm{cmH}_{2} \mathrm{O}(95 \% \mathrm{CI},-6.444$ to $8.160 ; P=$ 0.8047).

\section{Effect of TAS-303 on different urethral regions}

When the MUCP (Fig. 2) and mean urethral closure pressure (Fig. 3) at rest were separately analyzed for the proximal, middle, and distal thirds of the functional urethral length, no significant difference was found between TAS-303 and placebo in any region. However, among the three regions, the proximal part of the urethra, where $\alpha 1$ receptors are concentrated, showed the largest change, and the mean change in MUCP from before to after administration was larger with TAS-303 than with placebo (TAS-303: $3.863 \pm 10.941$ [ -1.967 to 9.693$]$, placebo: $1.634 \pm 12.093[-4.809$ to 8.078]).

\section{Safety}

No deaths or other serious AEs were reported, and no patients were withdrawn from the study because of AEs. The only AE observed in this study was a ligament sprain in one patient who received TAS-303 $18 \mathrm{mg}$, and this AE was considered to be unrelated to the study drug. No adverse drug reactions were reported for TAS-303 $18 \mathrm{mg}$. No clinically significant abnormal changes were observed in laboratory data (hematology, blood chemistry, and urinalysis). Similarly, no clinically 
Fig. 1 Disposition of patients with SUI

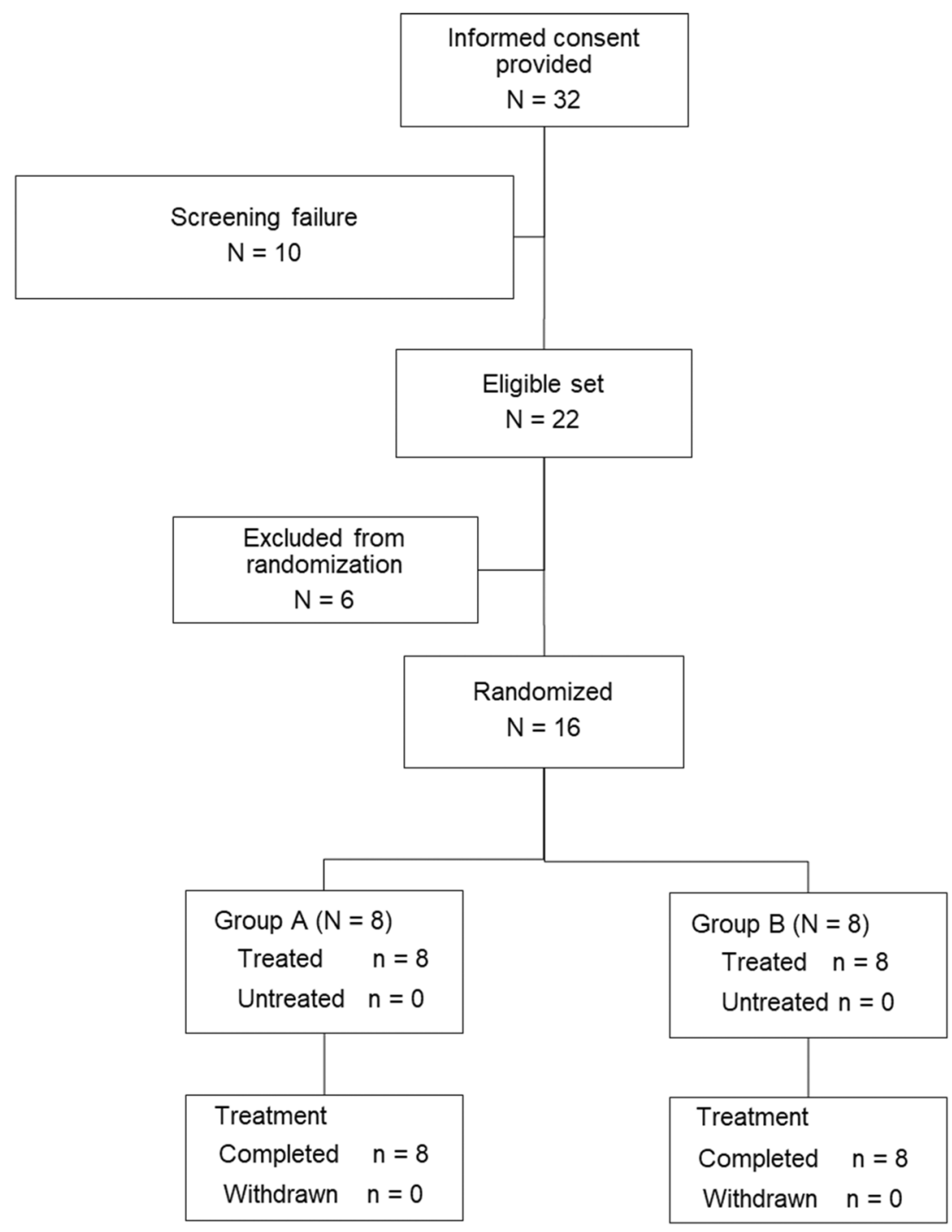

significant abnormal changes were observed in heart rate, pulse rate, and blood pressure.

\section{PK analysis}

The mean plasma concentration-time profile of TAS-303 is shown in Fig. 4. The PK parameters of TAS-303 administered as a single oral dose of $18 \mathrm{mg}$ under fasting conditions in patients with SUI are shown in Table 1.

\section{Discussion}

The change in MUCP at $6 \mathrm{~h}$ after administering TAS-303 $18 \mathrm{mg}$ was slightly higher in the TAS-303 group than in the placebo group; however, the difference was not statistically significant.

Although there was no significant difference in the MUCP change for each urethral region between TAS-303 $18 \mathrm{mg}$ and placebo, the amount of change in the proximal urethra was larger with TAS-303 $18 \mathrm{mg}$ than with placebo. This result suggested that TAS-303 may have stronger pharmacological effects on the proximal urethra. There was just one AE not related to TAS-303; there were no safety concerns and the drug was well tolerated. The mean plasma concentration-time profile of TAS-303 in the present study was similar to that in a previous single-dose study in healthy adult men (unpublished data).

In a previous preclinical study in rats treated with duloxetine and TAS-303, TAS-303 caused a dose-dependent increase in basal urethral pressure in normal rats and in leak point pressure in rats with vaginal distention in vivo [10].

TAS-303 $3 \mathrm{mg} / \mathrm{kg}$ produced an increase in urethral pressure in normal rats (by 38\% compared with vehicle), whereas duloxetine $1 \mathrm{mg} / \mathrm{kg}$ increased the urethral pressure by $15 \%$ compared with vehicle. The increase in leak point pressure with TAS-303 $3 \mathrm{mg} / \mathrm{kg}$ in vaginal distention (VD) rats was $26 \%$ and that with intravenous duloxetine $1 \mathrm{mg} / \mathrm{kg}$ was a $20 \%$ increase in VD rats. This result indicated that the effect of 


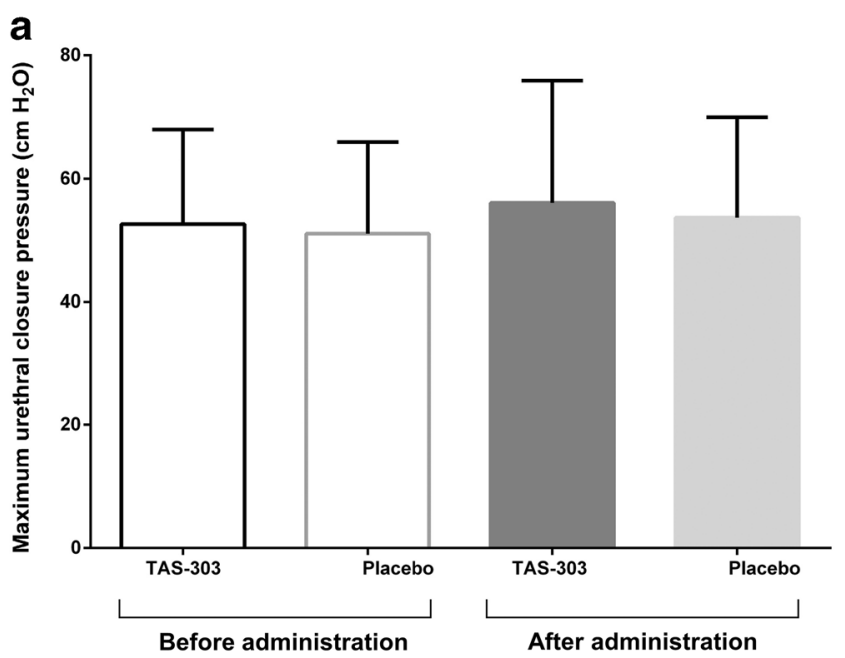

b
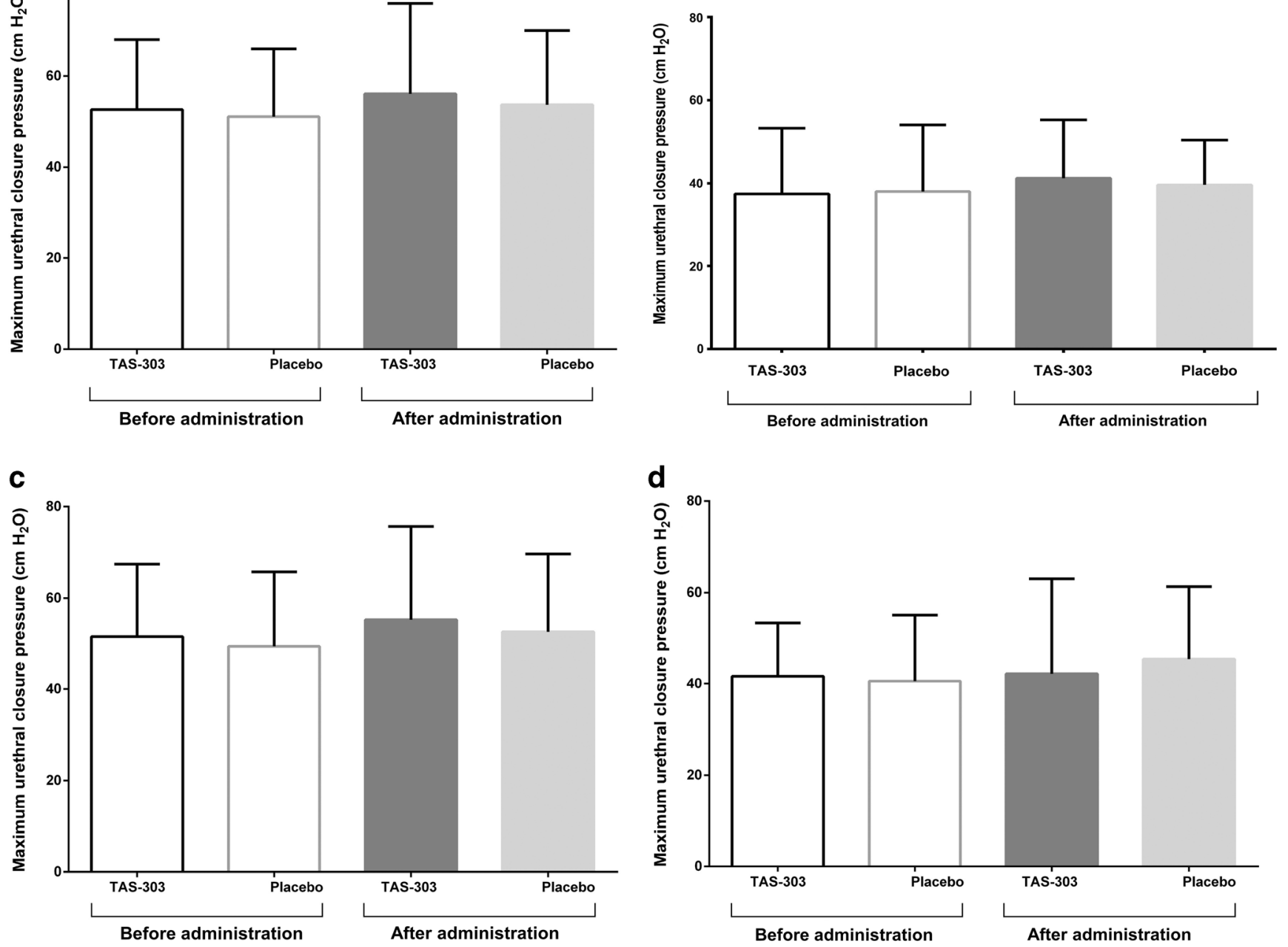

Fig. 2 Maximum urethral closure pressure at rest for the entire urethra (a) and for the proximal (b), middle (c), and distal urethral region (d) before and after administration of TAS-303 $18 \mathrm{mg}(n=16)$ or placebo $(n=16)$

TAS-303 administration on urethral pressure was comparable to that of duloxetine. Therefore, a difference from placebo in the main end point (MUCP) in this study was expected.

Furthermore, the proximal urethra is mainly composed of urethral smooth muscle in which $\alpha 1$ receptors are concentrated $[8,9]$. Therefore, we considered that TAS-303 administration could induce urethral contraction owing to $\alpha 1$ receptor stimulation by increasing the noradrenaline concentration in the urethra.

However, we did not find a statistically significant difference between TAS-303 and placebo in this study. The first reason for this result is that this study had a single-dose design, similar to a previous preclinical study [10] that showed a significant difference from placebo. The dose was selected as $18 \mathrm{mg}$ based on the previous preclinical study [10] and a single-dose study in healthy adult men that evaluated safety (unpublished data). The mean plasma concentration-time profile of TAS-303 in the present study was similar to that in a previous single-dose study in healthy adult men and it reached the expected level. However, in a preclinical study, $\mathrm{C}_{\max }$ was $17.7 \pm 5 \mathrm{ng} / \mathrm{mL}$ at an effective dose of $2.7 \mathrm{mg} / \mathrm{kg}$, whereas $\mathrm{C}_{\max }$ for SUI female patients was $42.341 \mathrm{ng} / \mathrm{ml}$, well above the preclinical concentration. Despite this, there was no significant difference from placebo. This may be related to differences in PK between animals and humans. The second reason is that the therapeutic range in humans may be higher than that in animals. In a $8-18 \mathrm{mg}$, repeated-dose study of TAS-303 conducted after this study, plasma concentration after once-daily repeated administration was maintained at five times the concentration reported after single-dose administration at the same doses [16]. Therefore, multiple doses may lead to sufficient blood concentration and have a significant difference from placebo. The third reason was that this study sample size may have been too small to permit confirmation of a significant difference. Fourth, as MUCP is more affected by the middle urethra than the proximal urethra, the measured pharmacological effect of TAS-303 on the proximal urethra may be lower than the actual effect [14]. Fifth, 11 out of 16 

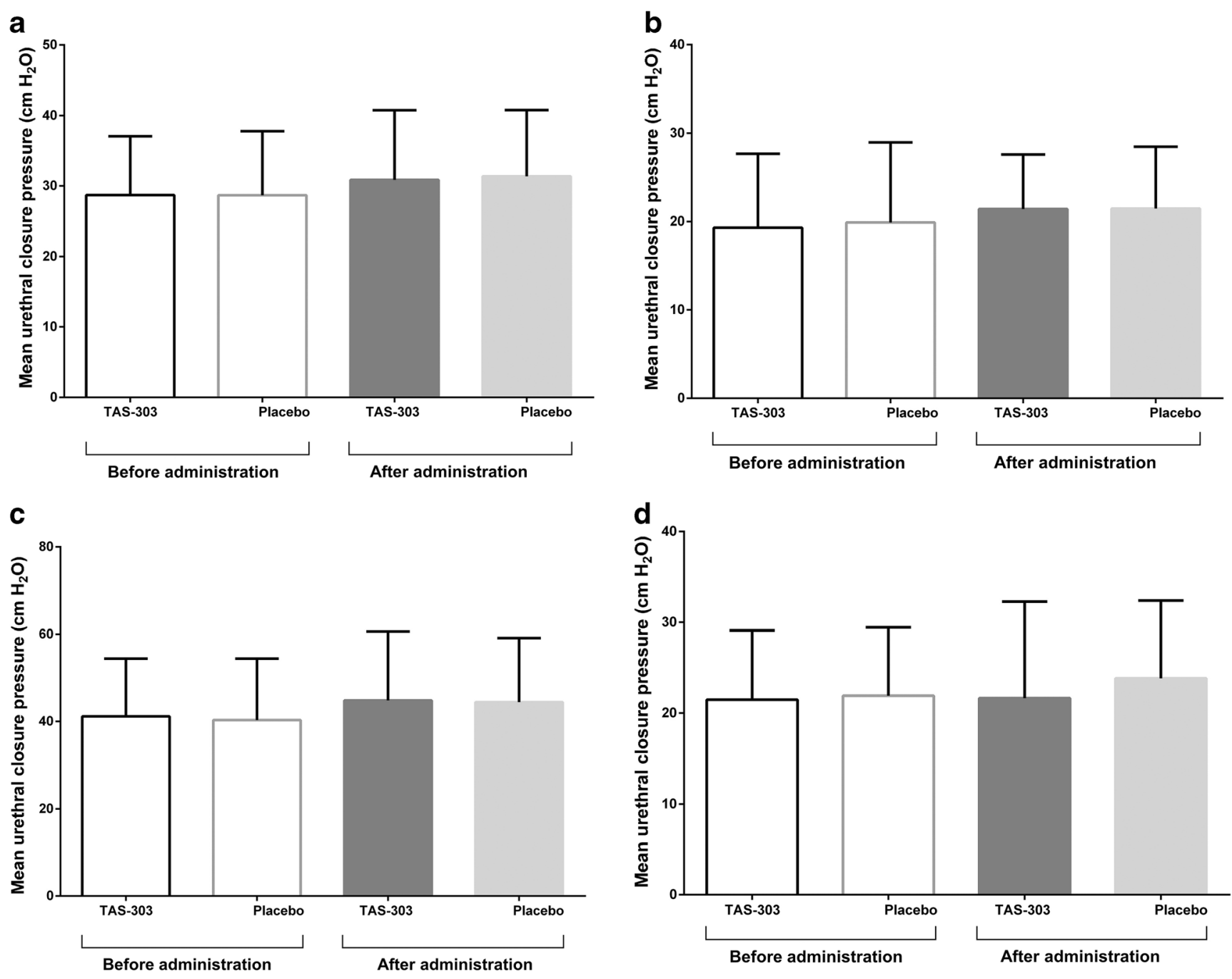

Fig. 3 Mean urethral closure pressure at rest for the entire urethra (a) and for the proximal (b), middle (c), and distal urethral region (d) before and after administration of TAS-303 $18 \mathrm{mg}(n=16)$ or placebo $(n=16)$

Fig. 4 Mean plasma concentration-time profile of TAS-303 in women with stress urinary incontinence (semilogarithmic scale) after administration of TAS-303

$18 \mathrm{mg}$. $N=16$, arithmetic mean \pm standard deviation

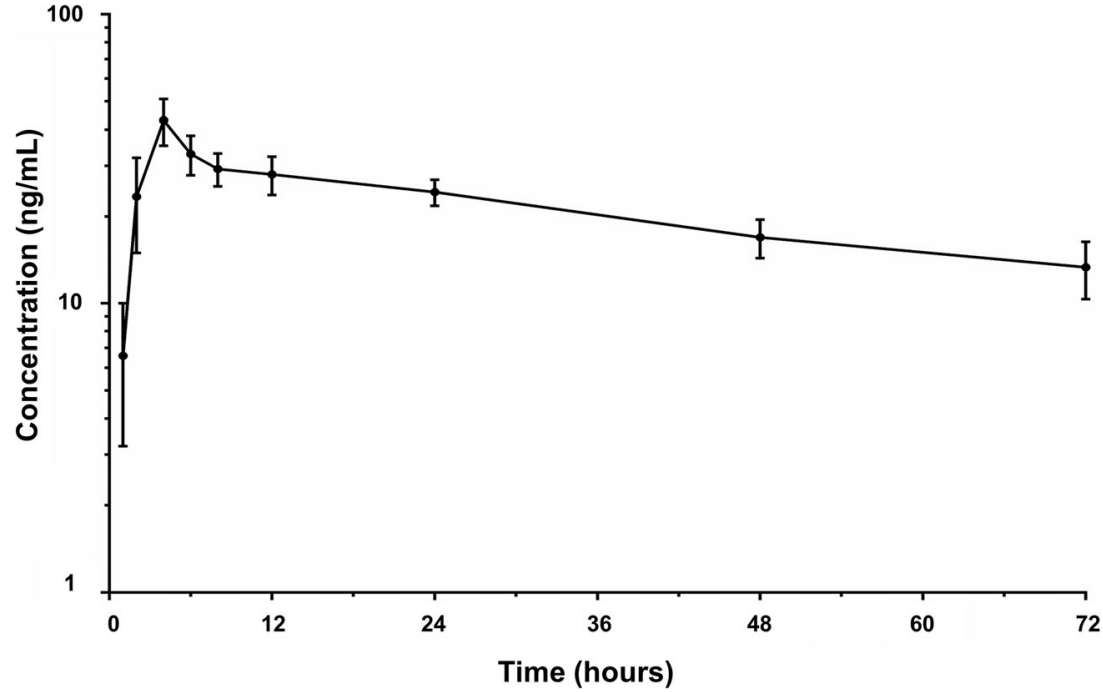


Table 1 PK parameters of TAS303 in patients with SUI

\begin{tabular}{llccl}
\hline & $\mathrm{C}_{\max }(\mathrm{ng} / \mathrm{ml})$ & $\mathrm{t}_{\max }(\mathrm{h})$ & $\mathrm{AUC}_{0-\mathrm{inf}}(\mathrm{ng} \bullet \mathrm{h} / \mathrm{ml})$ & $\mathrm{t}_{1 / 2}(\mathrm{~h})$ \\
\hline Geometric mean & 42.341 & $4.0(4.0-8.0)^{*}$ & 2677 & 57.76 \\
Geometric coefficient of variation $(\%)$ & 20.6 & $\mathrm{NA}$ & 31.4 & 41.6 \\
$\mathrm{~N}$ & 16 & 16 & 16 & 16 \\
\hline
\end{tabular}

*Median (minimum-maximum)

SUI, stress urinary incontinence; NA, not applicable; $\mathrm{C}_{\max }$, maximum plasma concentration; $t_{\max }$, time to maximum plasma concentration; $\mathrm{AUC}_{0-\text { inf }}$, area under the plasma concentration versus time curve from time zero to infinity; $\mathrm{t}_{1 / 2}$, elimination half-time

patient had menopause, and it may have negative impact on urethral contraction. Finally, in women with SUI, the urethral and para-urethral structures become progressively deficient. Intrinsic and extrinsic structural deficiencies result in a lower MUCP [14].

TAS-303 produced a larger change in the MUCP of the proximal urethra than the placebo, although the difference was not statistically significant. This suggested that TAS303 may have a pharmacological effect. To determine a significant difference, the measurement of MUCP in the proximal urethra in a study with a steady-state blood concentration of TAS-303 and a larger sample size may be required.

In terms of safety, although TAS-303 has the mechanism of action of noradrenaline reuptake inhibitor, it rarely crosses the blood-brain barrier [10], which has little effect on the central nervous system. Therefore, unlike duloxetine and other noradrenaline reuptake inhibitor such as Atmoxetine [17], TAS-303 has little nausea related to the central nerve system and has shown a good safety profile.

The present study had some limitations. First, the sample size was small. Second, as this study included only Japanese women with SUI, the results cannot be generalized to other ethnic populations. Third, 11 out of 16 patient had menopause.

The findings of this study suggest that TAS-303 has pharmacological effects in the proximal urethra. A double-blind phase II study of TAS-303 $18 \mathrm{mg}$ and placebo in women with SUI is currently planned, and its results are awaited in the hope that this will contribute to the treatment of patients with SUI in the future.

Author contributions Makoto Yono: Project development, data collection, data analysis, manuscript editing, manuscript writing.

Shin Irie: Project development, manuscript editing.

Momokazu Gotoh: Project development, data analysis, manuscript editing.

Funding information This study was funded by Taiho Pharmaceutical Co., Ltd.

\section{Compliance with ethical standards}

Conflict of interest MG declares having received consultancy fees from Taiho, Astellas, Kowa, and Kyorin and grants from Taiho, Pfizer,
Astellas, Daiichi Sankyo, Nihon Kayaku, Nippon Shinyaku, Takeda, and Asahikasei Pharma. All remaining authors have no conflicts of interest to declare.

Conference presentations International Continence Society, Florence, Italy, 12-15 September 2017.

Open Access This article is licensed under a Creative Commons Attribution 4.0 International License, which permits use, sharing, adaptation, distribution and reproduction in any medium or format, as long as you give appropriate credit to the original author(s) and the source, provide a link to the Creative Commons licence, and indicate if changes were made. The images or other third party material in this article are included in the article's Creative Commons licence, unless indicated otherwise in a credit line to the material. If material is not included in the article's Creative Commons licence and your intended use is not permitted by statutory regulation or exceeds the permitted use, you will need to obtain permission directly from the copyright holder. To view a copy of this licence, visit http://creativecommons.org/licenses/by/4.0/.

\section{References}

1. The International Continence Society (ICS) glossary of terminology. https://www.ics.org/glossary/symptom/ stressurinaryincontinence. Accessed 24 Dec 2019.

2. Fusco F, Abdel-Fattah M, Chapple CR, Creta M, La Falce S, Waltregny D, et al. Updated systematic review and meta-analysis of the comparative data on colposuspensions, pubovaginal slings, and midurethral Tapes in the surgical treatment of female stress urinary incontinence. Eur Urol. 2017;72:567-91.

3. van der Vaart CH, de Leeuw JR, Roovers JP, Heintz AP. The effect of urinary incontinence and overactive bladder symptoms on quality of life in young women. BJU Int. 2002;90:544-9.

4. Coyne KS, Zhou Z, Thompson C, Versi E. The impact on healthrelated quality of life of stress, urge and mixed urinary incontinence. BJU Int. 2003;92:731-5.

5. Thüroff JW, Abrams P, Andersson KE, Artibani W, Chapple CR, Drake MJ, et al. EAU guidelines on urinary incontinence. Eur Urol. 2011;59:387-400.

6. Burkhard FC, Bosch JL, Cruz F, Lemack GE, Nambiar AK, Thiruchelvam N, Tubaro A, Ambühl D, Bedretdinova DA, Farag F, Lombardo R, Schneider MP (2019) EAU guidelines on urinary incontinence in adults. https://uroweb.org/wp-content/uploads/ EAU-Guidelines-on-Urinary-Incontinence-2019.pdf

7. Takahashi S, Takei M, Nishizawa O, Yamaguchi O, Kato K, Gotoh $\mathrm{M}$, et al. Clinical guideline for female lower urinary tract symptoms. Low Urin Tract Symptoms. 2016;8:5-29. 
8. Mørkved S, Bø K. Effect of postpartum pelvic floor muscle training in prevention and treatment of urinary incontinence: a one-year follow up. BJOG. 2000;107:1022-8.

9. Ozawa H (2008) Stress urinary incontinence. In: Kato K (Ed.) care for urinary incontinence and female urological diseases. Osaka: Medicus Shuppan, publishers co., pp 230-231.

10. Mizutani H, Sakakibara F, Komuro M, Sasaki E. TAS-303, a novel selective norepinephrine reuptake inhibitor that increases urethral pressure in rats, indicating its potential as a therapeutic agent for stress urinary incontinence. J Pharmacol Exp Ther. 2018;366:322_31.

11. European Medical Agency (2013) Guideline on the clinical investigation of medicinal products for the treatment of urinary Incontinence. http://www.ema.europa.eu/docs/en GB/document library/Scientific_guideline/2013/07/WC500146177.pdf. Accessed 24 Dec 2019.

12. Yono M, Otani M, Ito K, Inoue Y, Furukawa K, Hori M, et al. Effect of duloxetine on urethral resting pressure and on sphincter contractility in response to coughing and magnetic stimulation in healthy women. Low Urin Tract Symptoms. 2015;7:93-8.

13. Karam I, Droupy S, Abd-Alsamad I, Uhl JF, Benoît G, Delmas V. Innervation of the female human urethral sphincter: $3 \mathrm{D}$ reconstruction of immunohistochemical studies in the fetus. Eur Urol. 2005;47:627-33.

14. Pajoncini C, Costantini E, Guercini F, Porena M. Intrinsic sphincter deficiency: do the maximum urethral closure pressure and the Valsalva leak-point pressure identify different pathogenic mechanisms? Int Urogynecol J Pelvic Floor Dysfunct. 2002;13:30-5.

15. Abrams P, Cardozo L, Fall M, Griffiths D, Rosier P, Ulmsten U, et al. The standardisation of terminology in lower urinary tract function: report from the standardisation sub-committee of the International Continence Society. Urol. 2003;61:37-49.

16. Hanada R. Safety and pharmacokinetics of high-dose TAS-303 in healthy Japanese volunteers: a single-center, single-blind, randomized, placebo-controlled, parallel-group, multiple-ascending-dose study. Clin Pharmacol Drug Dev. 2020. https://doi.org/10.1002/ cpdd.801.

17. Kielbasa W, Kalvass JC, Stratford R. Microdialysis evaluation of atomoxetine brain penetration and central nervous system pharmacokinetics in rats. Drug Metab Dispos. 2009;37:137-42.

Publisher's note Springer Nature remains neutral with regard to jurisdictional claims in published maps and institutional affiliations. 